\title{
Effect of Bacterial Cell Moisture on the Sporicidal Activity of $\beta$-Propiolactone Vapor
}

\author{
ROBERT K. HOFFMAN \\ Department of the Army, Fort Detrick, Frederick, Maryland 21701
}

Received for publication 19 January 1968

\begin{abstract}
The activity of a vapor-phase disinfectant is usually expressed in terms of the atmospheric relative humidity $(\mathrm{RH})$. This study shows that, in $\beta$-propiolactone (BPL) vapor disinfection, the important factor is really the moisture content and location of water in the cell, and not necessarily the atmospheric RH. Previous studies revealed that only about $50 \%$ of the bacterial spores equilibrated to $45 \% \mathrm{RH}$ were killed when exposed to the same RH to BPL vapor. On the other hand, all the spores equilibrated to and then exposed at $75 \% \mathrm{RH}$ to BPL were readily killed. The present study shows that spores equilibrated to $98 \% \mathrm{RH}$ are readily killed by BPL at $45 \% \mathrm{RH}$, but only $99 \%$ of the spores equilibrated to $75 \% \mathrm{RH}$ are killed by BPL at $45 \% \mathrm{RH}$. Also, in order to be killed, desiccated spores must be exposed to BPL at higher humidities than would be required if the spores had not been previously desiccated.
\end{abstract}

$\beta$-Propiolactone (BPL) was shown by Hoffman and Warshowsky (4) to be an effective vapor phase disinfectant; however, its activity was very dependent on the atmospheric humidity. For example, the chemical showed great activity at relative humidities (RH) of 75 and $85 \%$, considerable activity at $60 \% \mathrm{RH}$, and little activity at $45 \% \mathrm{RH}$. No data are presented for $\mathrm{RH}$ values above $85 \%$. We suspected that the amount of moisture as well as its location within the cell, and not necessarily the amount of water in the atmosphere surrounding the cell, are really the significant factors regulating the rate at which BPL kills the cell. Bateman et al. (1) and Gilbert et al. (3) showed that the amount of moisture in a bacterial cell depends not only on the RH of the atmosphere surrounding the cell, but also on the past history of the cell, i.e., whether or not the cell was previously subjected to desiccation. Their studies revealed that cells have less moisture when equilibrated from a highly desiccated state to a higher RH (except at saturation RH) than do cells that have been equilibrated to the same $\mathrm{RH}$ starting from the wet state. A similar hysteresis effect was shown by Katchman and McLaren (6) for tobacco mosaic virus. As far back as 1936, Speakman and Cooper reported the same hysteresis effect with wocl (10).

The recent work of Gilbert et al. (3) tends to dispell the hypothesis that it is only the amount of cellular water that regulates the rate of microbial inactivation by ethylene oxide. Their results lead one to suspect that it is also the location of the water in the cell that is involved.

The present work was conducted to show the effect bacterial cell moisture content has on the rate at which cells are inactivated by BPL.

\section{Materials AND Methods}

Preparation of test microorganisms and samples. The effect of cell moisture content on the activity of BPL vapor was shown by the rate at which bacterial spores preconditioned to humidity are killed when exposed to the chemical vapor at various RH values.

The test organisms were Bacillus subtilis var. niger (Bacillus globigii) spores. They were grown in liquid casein acid digest media, harvested by centrifugation, washed, suspended in water, and heat-shocked at $60 \mathrm{C}$ for $30 \mathrm{~min}$ to kill the less resistant vegetative cells. Small cotton or Whatman no. 42 filter paper patches were contaminated with $0.1 \mathrm{ml}$ of $B$. subtilis var. niger spore suspension adjusted to give a final concentration of 1 to 10 million viable spores per patch. The patches were then transferred to desiccators. To give the desired $\mathrm{RH}$ for preconditioning at $25 \mathrm{C}$, the desiccators were charged with the following saturated salt solutions: potassium dichromate, $98 \% \mathrm{RH}$; potassium chloride, $85 \% \mathrm{RH}$; sodium chloride, $75 \% \mathrm{RH}$; and nickel chloride, $53 \% \mathrm{RH}$.

Anhydrous calcium sulfate was used in another desiccator to give an RH of less than $1 \%$. The contaminated patches were preconditioned to the desired RH for approximately 1 week prior to use for test purposes.

Exposure to BPL vapor. The first experiment (A) was carried out in a modified 10-liter desiccator, 
whereas the other was carried out in a large chamber in which both the temperature and RH could be controlled (experiment B).

In experiment $\mathbf{A}$, the preconditioned contaminated patches were placed in the modified desiccator, and the RH therein was adjusted rapidly to the desired level by flushing with air of the same RH. The RH of the air was regulated by blending the correct proportions of two air streams, one being saturated by passing through water and the other dehydrated by passing through a drying column containing calcium sulfate. A wet-dry bulb apparatus attached to the downward side of the modified desiccator was used to determine when the desired RH was attained. Once the desired RH was achieved, a slight but predetermined negative pressure was drawn in the chamber; then the pressure was returned to atmospheric by bleeding in BPL vapor. The use of such a chamber permits only one BPL exposure time per test because it is necessary to remove the top of the desiccator to retrieve the patches. Once opened, the internal conditions are completely altered. This technique requires numerous tests to establish a death rate. Periodically, the air in the desiccator was checked for BPL content just before opening to retrieve the patch for assay.

Experiment B was conducted in a 1,700-liter chamber. In this chamber, the temperature, $\mathbf{R H}$, and BPL concentrations were first adjusted, then a long rod was inserted with a number of spore-contaminated patches attached by pins. Periodically, the rod was withdrawn only far enough to permit removal of several patches for assay. In this way, a complete death rate study was conducted in one chamber experiment.

Both control patches (inoculated with the microorganism but not exposed to BPL) and exposed patches were assayed by immersion in dilution blanks containing $0.1 \%$ sodium thiosulfate (to neutralize any BPL carried over on the patch) and $0.05 \%$ Tween 20 (to aid in the removal of organisms from the patch). Each dilution blank was shaken vigorously, and samples were plated in nutrient agar. All plates were incubated for $48 \mathrm{hr}$ at $37 \mathrm{C}$ before counting. Duplicate patches were used for each test point, and each test was repeated three times.

The following protocols were used. Experiment A: Microorganisms were preconditioned on patches to $1 \% \mathbf{R H}$, and death rates were determined upon exposure to BPL at 75,85 , or $92 \%$ RH. Experiment B: Microorganisms were preconditioned on patches to 98,75 , and $53 \% \mathrm{RH}$, and death rates were determined upon exposure to BPL vapor at $45 \% \mathrm{RH}$.

\section{Results AND Discussion}

The results shown in Fig. 1 to 3 indicate that the moisture content of the microorganism is of major importance in regulating the rate at which the spores are inactivated by BPL. Only 40 to $50 \%$ of the spores preconditioned to $45 \% \mathrm{RH}$ and then exposed to BPL at the same RH were killed by the chemical vapor (Fig. 1). Yet all of the spores were killed by BPL at $45 \% \mathrm{RH}$ if they

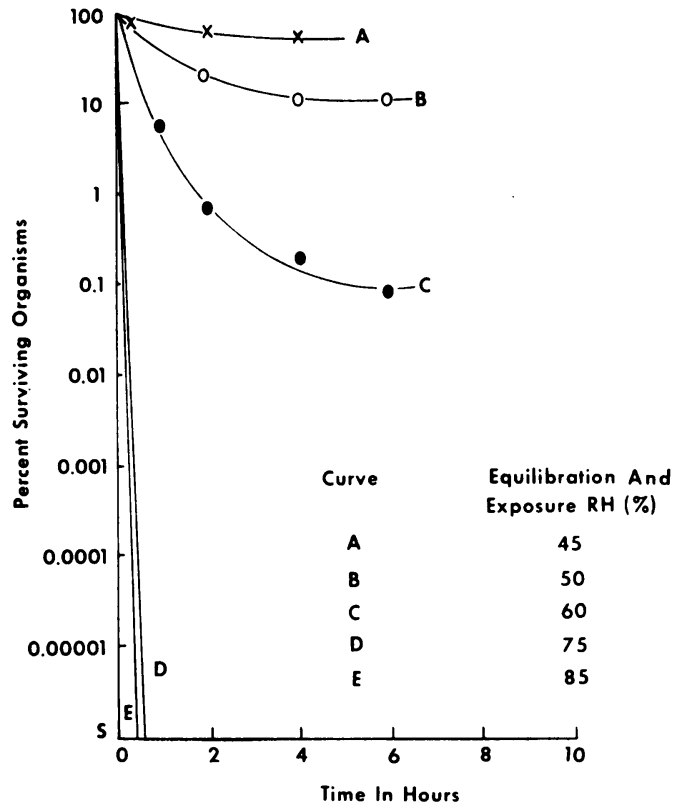

FIG. 1. Effect of relative humidity (RH) on death rate of Bacillus subtilis var. niger spores exposed to $1.5 \mathrm{mg}$ of $\beta$-propiolactone per liter at $27 \mathrm{C}$.

were first preconditioned at $98 \%$ RH (Fig. 2). Even so, the rate at which the cell loses moisture at a lower RH is quite rapid. Cells preconditioned at $75 \%$ were killed fairly rapidly at first and then with diminished rapidity until there was no further kill after a $\mathbf{9 9 \%}$ reduction. This contrasts with the rapid and complete kill of spores equilibrated at $75 \% \mathbf{R H}$ and then exposed to BPL at 75\% RH (Fig. 1).

The importance of cell moisture in BPL sterilization was further emphasized by the fact that a small percentage of spores preconditioned at $1 \%$ RH were thereafter very resistant to BPL sterilization at $75 \%$ RH (Fig. 3). This was the same effect noted with ethylene oxide (3); in that case, however, the resistance to sterilization by ethylene oxide was overcome only by first subjecting the cells to drastic measures, such as physically wetting with water or equilibrating the organisms for 4 to 6 days at 98 and $75 \% \mathrm{RH}$, respectively. On the other hand, with BPL it was much easier to overcome the resistance. Merely exposing the cells to BPL at about $92 \%$ RH was sufficient, and no wetting or previous lengthy preconditioning to a high RH was required.

Gilbert et al. (3) showed (Fig. 4) that B. subtilis spores equilibrated at $25 \mathrm{C}$ from a wet spore suspension to $75 \%$ RH contained about $23 \%$ moisture, whereas cells that were desiccated and then conditioned to $75 \% \mathbf{R H}$ contained only 
about $19 \%$ moisture. The cell on the adsorption curve must now be equilibrated to about $85 \%$ RH to contain $23 \%$ moisture. This $\mathbf{R H}$ approaches but does not quite meet that needed to overcome the resistance to BPL sterilization after the cell was subjected to desiccation (Fig. 3). This fact would make it appear that, although the

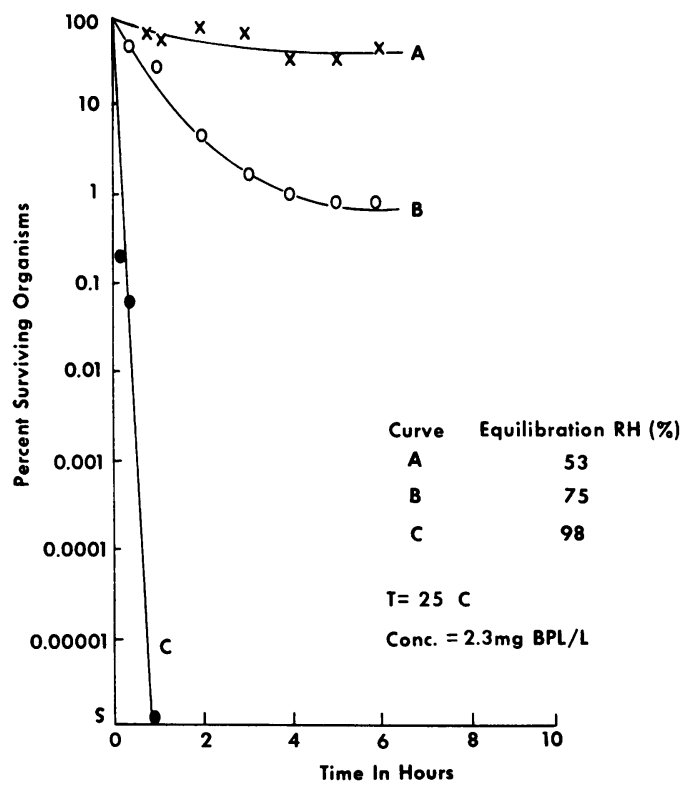

FIG. 2. Rate of kill of Bacillus subtilis var. niger spores equilibrated to 98,75 , and $53 \%$ relative humidity $(R H)$ and exposed to $\beta$-propiolactone (BPL) vapor at $45 \% R H$. amount of moisture present in the cell is of prime importance, its location is also of extreme importance in regulating the rate at which the cell is killed by BPL.

The curves shown in Fig. 1 were obtained with bacterial spores equilibrated from a wet suspension. Therefore, the cells equilibrated to $60 \% \mathrm{RH}$,

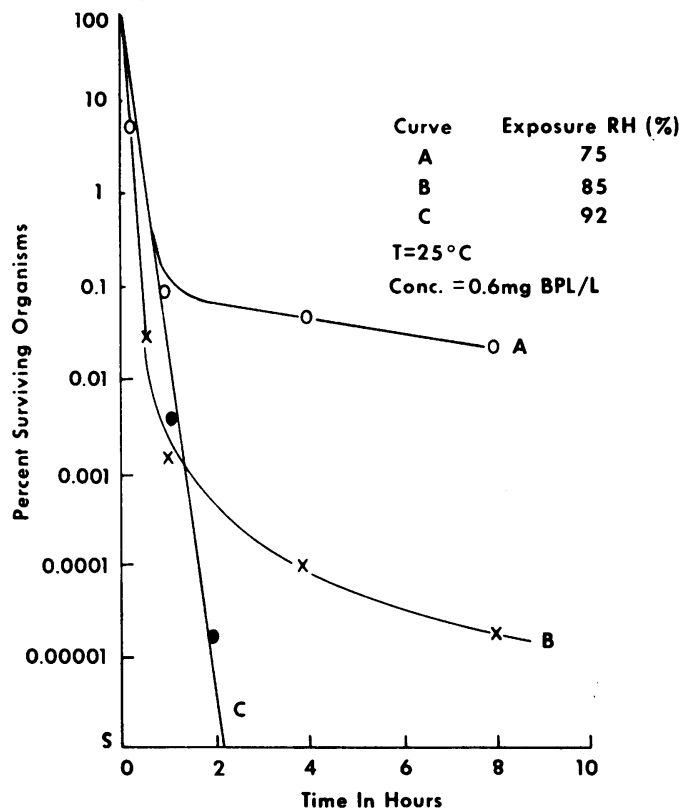

Fig. 3. Rate of kill of Bacillus subtilis var. niger spores equilibrated to $1 \%$ relative humidity $(R H)$ and exposed to $\beta$-propiolactone (BPL) vapor at 92,85 , and $75 \% R H$.

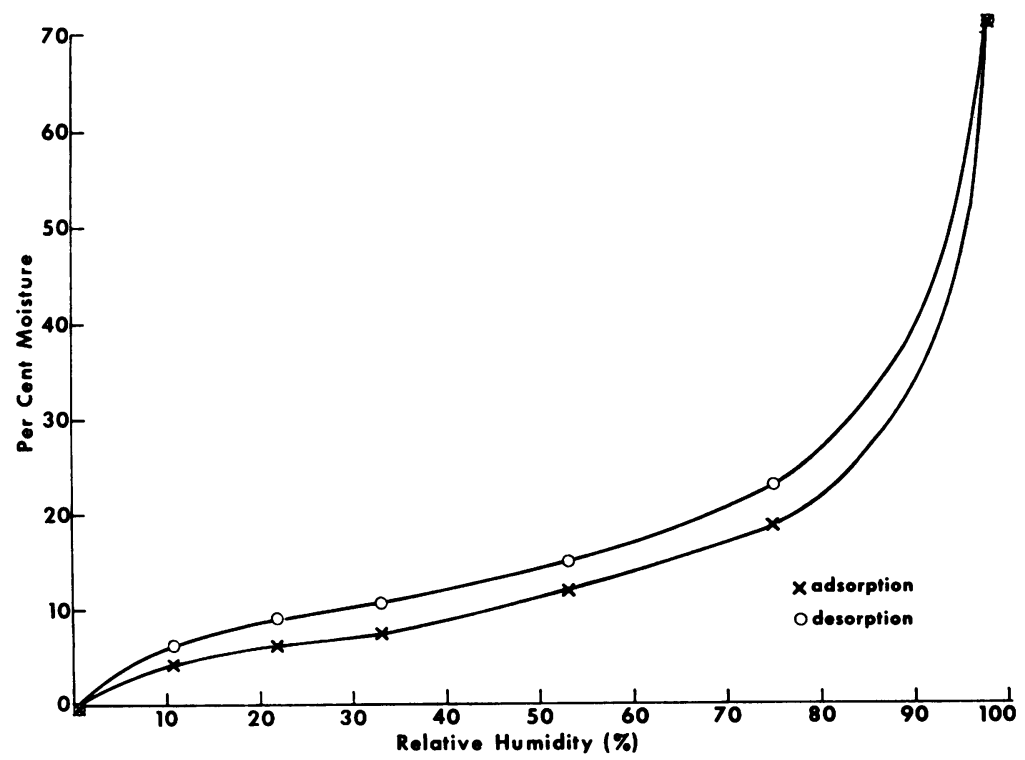

FIG. 4. Moisture content of Bacillus subtilis spores as a function of relative humidity at $25 \%$. 
according to Fig. 4, would contain abott $18 \%$ moisture. Curve A, Fig. 3, was obtained at $75 \%$ RH but closely resembles the $60 \%$ RH curve (C) in Fig. 1. Actually, the spores used to obtain the A curve of Fig. 3 were tested at $75 \% \mathrm{RH}$, but this was after the cells were desiccated. Such cells, when in equilibrium at $75 \% \mathrm{RH}$, also should contain 18 to $19 \%$ water. Thus, the cell moisture content would be the same in both cases and the curves would resemble each other, but only if the rate of moisture transfer into the cell is quite rapid. The similarity of the curves verifies the rapid moisture transfer into the cell.

The role of moisture in BPL cell inactivation is not clear. Furthermore, it is even more difficult to explain in the light of ethylene oxide, a chemical that presumably inactivates by the same mechanism as BPL but requires little water to kill the cell. Ethylene oxide is most active at about $30 \%$ RH (7); however, even at much lower RH values, ethylene oxide will kill $99.9 \%$ of the cells thus exposed (3). BPL is a very reactive chemical and should require no more water than does ethylene oxide to alkylate the various protein groups, but an RH of $70 \%$ or higher is needed for greatest BPL activity. Black and Gerhardt (2) proposed the hypothesis that the dormant spore has an outer, fully permeable coat, a cortex that is possibly lipid-like, and a dense core that is an insoluble and heat-stable gel. The core is thought to be permeable only to small molecules, while the cortex is thought to be permeable to water and small lipophilic solutes. BPL requires a high cell-moisture content to inactivate, perhaps because water, or some cell constituent solubilized by it, acts as a transport agent. The possible lipid-like nature of the cortex and the density of the core could conceivably require more moisture for the transport of the slightly larger and less lipid-soluble BPL molecule to the site or sites of reaction than is required for ethylene oxide. If this is the case, it would further indicate that the location of the water in the cell is of extreme importance.

The mechanism by which BPL inactivates the bacterial cell has not been definitely established. BPL is a very reactive chemical and can alkylate many terminal groups found on protein molecules, such as amino, imino, hydroxyl, and carboxyl radicals $(\mathrm{H}$. W. Jones and $\mathrm{H}$. P. Lundgren, U.S. Patent 2,517,573, 1950). Searle (9) showed that BPL reacts with thiol and disulfide groups in albumin. Ichikawa et al. (5) concluded from their studies that BPL will react with sulfhydryl groups of enzyme proteins as well as the $N_{7}$ position of the RNA or DNA guanine moiety. Roberts and Warwick (8) previously suggested the latter as the site of BPL reaction. More recent studies with other alkylating agents, such as ethylene oxide and propylene oxide, also implicate the $\mathrm{N}_{7}$ guanine position as the main site of reaction in RNA or DNA. It remains to be determined, however, whether a microorganism is inactivated by one or several alkylations of a vital site in the cell or whether it requires one or a number of alkylations of amino, sulfhydryl, hydroxyl, or carboxyl protein radicals, thus generally poisoning the cell. Whatever the lethal reaction between BPL and the microbial cell, it obviously cannot proceed without considerable water in the right location.

\section{ACKNOWLEDGMENT}

The skilled technical assistance of MSG George L. Gilbert and Beatrice C. Rowe is gratefully acknowledged.

\section{Literature Cited}

1. Bateman, J. B., C. L. Stevens, W. B. Mercer, AND E. L. CARSTEnSEN. 1962. Relative humidity and the killing of bacteria; the variation of cellular water content with external relative humitity or osmolality. J. Gen. Microbiol. 29:207-219.

2. Black, S. H., and P. Gerhardt. 1962. Permeability of bacterial spores. IV. Water content, uptake, and distribution. J. Bacteriol. 83:960967.

3. Gilbert, G. L., V. M. Gambill, D. R. Spiner, R. K. Hoffman, and C. R. Phillips. 1964. Effect of moisture on ethylene oxide sterilization. Appl. Microbiol. 12:496-503.

4. Hoffman, R. K., AND B. Warshowsky. 1958. Beta-propiolactone vapor as a disinfectant. Appl. Microbiol. 6:358-362.

5. Ichikawa, Y., S. Utsumi, and K. KURisu. 1967. Studies on the antimicrobial action of propionate and related substance. Part I. The mechanism of the microbial action of $\beta$-propiolactone. Kyoto Univ. Ind. Arts Textile Fibers 41:84-93.

6. Katchman, B., and A. D. McLaren. 1951. Sorption of water vapor by proteins and polymers. IV. J. Am. Chem. Soc. 73:21242127.

7. Kaye, S., and C. R. Phillips. 1949. The sterilizing action of gaseous ethylene oxide. IV. The effect of moisture. Am. J. Hyg. 50:296306.

8. Roberts, J. J., AND G. P. WARWICK. 1963. The reaction of $\beta$-propiolactone with guanine, desoxyguanylic acid and RNA. Biochem. Pharmacol. 12:1441-1442.

9. Searle, C. E. 1961. Polarographic experiments on the interaction of $\beta$-propiolactone with albumin thiol and disulphide groups. Biochim. Biophys. Acta 52:579-582.

10. Speakman, J. B., and C. A. Cooper. 1936. The adsorption of water by wool. Part I. Adsorption hysteresis. J. Textile Inst. Trans. 27: T183-T185. 